\title{
Imaging the pituitary in psychopathologies: a review of in vivo magnetic resonance imaging studies
}

\author{
Chloe Anastassiadis $^{1}\left[\right.$ ] Sherri Lee Jones ${ }^{2} \cdot$ Jens C. Pruessner ${ }^{3}$
}

\begin{abstract}
The pituitary gland (PG) is a key component of the essential endocrine systems in humans and animals, including the hypothalamic-pituitary-adrenal, hypothalamic-pituitary-gonadal, and hypothalamic-pituitary-thyroid axes. Structural changes in the PG are observed in a number of psychiatric disorders. Psychiatric disorders are typically characterized by subtle, time-dependent anatomical changes in the brain, and their study necessitates highly powered, longitudinal investigations. Structural magnetic resonance imaging (MRI) is a non-invasive technology that is ideally suited to detect changes in anatomical structures over time. In this paper, we will review the main findings on pituitary function and structure in the context of healthy development and of psychiatric disorders, with particular emphasis on MRI studies. The latter have not always succeeded in providing a clear theoretical framework of mental disorders, which may be explained by low resolution and differences in preprocessing methods, imprecise segmentation rules that do not account for the anatomical and functional specificity of the anterior and posterior lobes of the PG, and inadequate categorization of clinical subjects. We review those limitations and propose solutions for future research.
\end{abstract}

Keywords Magnetic resonance imaging $\cdot$ Manual segmentation $\cdot$ Pituitary $\cdot$ Psychopathology $\cdot$ Volumetric analysis

\section{Introduction}

In 1886, a case of acromegaly got scientists to recognize the function of the pituitary gland (PG), also known as the hypophysis, for the first time (Musumeci et al. 2015). The PG, often referred to as the body's "master gland", is critical for the regulation of endocrine activity, and subsequent behavior and development. It receives hypothalamic signals, and together these structures coordinate the control of three complex neuroendocrine systems: the hypothalamicpituitary-gonadal (HPG), the hypothalamic-pituitary-adrenal (HPA), and the hypothalamic-pituitary-thyroid (HPT) axes (Castaneda Cortés et al. 2014). Those systems, which are often perturbed in neuropsychiatric disorders, regulate

Chloe Anastassiadis

chloe.anastassiadis@mail.mcgill.ca

1 Douglas Mental Health University Institute, McGill University, 6875 Boulevard LaSalle, Verdun, QC H4H 1R3, Canada

2 McGill University Health Center, McGill University, Montreal, QC, Canada

3 University of Konstanz, Constance, Germany reproductive behavior, the stress response, and metabolism, respectively (Chrousos and Gold 1992; Fekete and Lechan 2014; Smith and Vale 2006). Ablation studies and histological work have shown that those neuroendocrine functions are spatially compartmentalized in both the hypothalamus and the PG. The human PG, in particular, can be divided into at least two lobes (the adeno- and the neurohypophysis) that are distinct by their position along the rostro-caudal axis, as well as their size, and functions (Hong et al. 2016). Magnetic resonance imaging (MRI) has proven promising for characterizing structural abnormalities of the whole PG in several neuropsychiatric disorders, including schizophrenia (Atmaca 2014), depression (Arnone et al. 2012), and eating disorders (Doraiswamy et al. 1991). Here we summarize the contributions and limitations of those studies and propose future directions of structural MRI to elucidate the role of the PG in psychopathologies. Whereas others have focused mostly on the heterogeneity of the clinical findings (e.g., Atmaca 2014; Delvecchio et al. 2017), in this review we will also give special consideration to the structure and function of the PG and its appearance on MRI, and make the case for a more biologically and anatomically informed study of its two lobes. 


\section{Contributions of ablation experiments and postmortem studies}

\section{The anterior and posterior PG differ in their gross anatomy and microscopic structure}

\section{Gross anatomy}

As early as in the second century AD, Galen described the PG and its stalk, based on his own dissections of animals (Toni 2000). The Greek physician assumed that the gland worked as a receptacle for "mucus" (Laios et al. 2017). Although his incorrect theories about the function of the PG were not seriously challenged until the seventeenth century (Toni 2000), there has been a reasonably good understanding of the anatomy of the gland since the Renaissance, obtained through postmortem examination of

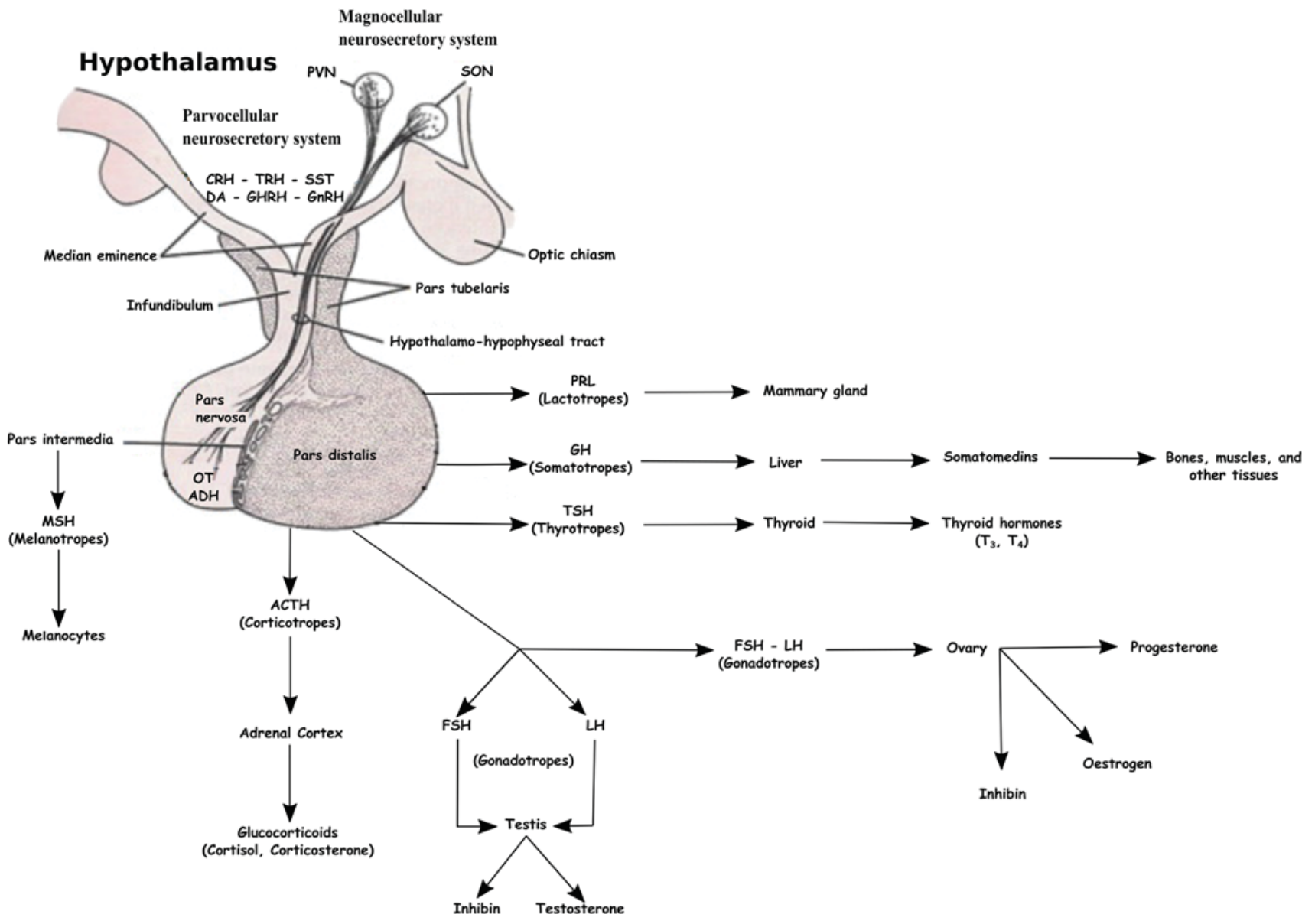

Fig. 1 Hormones released by the adenohypophysis and pars intermedia and their respective targets. Under the action of the hypothalamus, the anterior PG releases hormones to the adrenal cortex, thyroid, and gonads as part of the main endocrine axes responsible for the stress reaction, the regulation of metabolism, and reproductive behavior, respectively. The liver and mammary glands are also targets of the human bodies (Lechan and Toni 2000). The PG is situated in the fossa hypophysialis, a cavity bounded by the sella turcica (Menon et al. 2011). The latter is a depression of the sphenoid bone, situated at the base of the skull and just inferior to the suprasellar cistern and the hypothalamus (Menon et al. 2011; Pantalone et al. 2015). The bony sella is covered by dura mater and surrounded by the mucous membrane of the air-filled sphenoid sinus inferiorly and the inner dural layer of the venous cavernous sinuses laterally (Castillo 2005; Ouyang et al. 2011; Rhoton 2002).

As shown in Fig. 1, the PG is connected to the median eminence of the hypothalamus via the pituitary stalk (PS), also known as the infundibulum, which comprises both a neuronal and a vascular component (Delman 2009; McCann 1992) and passes through the roof of the sella, the diaphragm sellae (Rhoton 2002). The vascular component, discovered by Popa and Fielding in 1930, is called the hypophyseal portal system (McCann 1992). anterior PG. The posterior PG (pars nervosa) releases oxytocin (OT) and the antidiuretic hormone $(\mathrm{ADH})$, which regulate social behavior and water balance and metabolism, respectively. Reprinted from A journey through the pituitary by Musumeci et al. (2015) Copyright 2015 Elsevier GmbH. Reprinted with permission 
Anatomical studies on the living toad a few years later found that the hypophyseal portal system supplied blood to the PG from the hypothalamus, suggesting hypothalamic control of the PG (McCann 1992). This portal system receives its input from a network of capillaries in the median eminence, which itself arises from a branch of the internal carotid artery, the superior hypophyseal artery (McCartney and Marshall, 2019). Now we know that the hypophyseal portal system supplies only the anterior PG, or adenohypophysis, which represents about $80 \%$ of the whole PG mass (Fountas and Karavitaki 2017) and 70\% of its length (Ju et al. 2010). The anterior PG comprises the pars distalis, intermedia, and tuberalis (Menon et al. 2011), with the latter being the continuation of the hypophyseal portal system (Castillo 2005). The human pars intermedia is ill defined (Yeung et al. 2006) and often considered almost vestigial in human adults (Amar and Weiss 2003). The posterior PG is the extension of the neuronal component of the PS or infundibulum (Fig. 1), as first discovered by Ramon y Cajal in 1894 (Lechan and Toni 2000), and is a circumventricular organ (i.e., situated outside the blood-brain barrier) (Kiecker 2017). It may be referred to as the pars nervosa or infundibular process (Castillo 2005), and, combined with the infundibulum, as the neurohypophysis (Menon et al. 2011). The latter term sometimes also includes the median eminence of the hypothalamus (Castillo 2005). The posterior PG receives direct vascular inputs through the inferior hypophyseal artery, another branch of the internal carotid arteries (Lechan et Toni 2000).

\section{Microscopic structure}

The anterior PG contains five main endocrine cell types, differentiated by the hormones they secrete and their location (Le Tissier et al. 2012): the somatotropes (50\% of the cells), corticotropes (10-20\%), and lactotropes (10-25\%) in the pars distalis, and the gonadotropes (10\%) and thyrotropes $(5 \%)$ in the pars tuberalis and the pars distalis (Ben-Shlomo and Shlomo 2017; Dada et al. 1984; Eagle and Tortonese 2000; Lechan and Toni 2000; Menon et al. 2011; Morgan and Williams 1996; Yeung et al. 2006) (Fig. 1). There are also melanotropes in the pars intermedia (Menon et al. 2011), and non-hormonal folliculostellate cells (Yeung et al. 2006). The posterior lobe of the PG is constituted by axons originating in the supraoptic (SON) and paraventricular (PVN) nuclei of the hypothalamus (Musumeci et al. 2015), and also contains supporting neuroglial cells, the pituicytes (Castillo 2005). During the first half of the twentieth century, the functions of both lobes were intensively studied, using mostly ablation/ implant studies on animals.

\section{The anterior and posterior PG differ in function}

\section{Anterior PG}

Ablation/implant studies on animals uncovered the complex dynamics between the hypothalamus, the PG, and other glands through forward commands and feedback loops. Three circuits involving the hypothalamus and the anterior PG were found to control basic functions of the HPG, HPA, and HPT axes. The HPG axis regulates reproductive functions. The pars tuberalis of the anterior PG secretes luteinizing hormones (LH) and follicle-stimulating hormones (FSH) (Menon et al. 2011) in response to hypothalamic release of gonadotropin-releasing hormones (GnRH) via the hypophyseal portal system (Hong et al. 2016). LH and FSH stimulate the gonads, which in turn release sex steroid hormones, such as estradiol or testosterone. Sex steroids affect reproductive behavior, body mass, and bone density (Hong et al. 2016). The existence of a negative feedback loop from the gonads to the PG was hypothesized by Moore and Price when they observed that injecting male or female gonadal hormones into castrated males had a "depressing effect upon the hypophysis" (Moore and Price 1932). The anterior PG also participates in the fight-or-flight response mediated by the HPA axis (Bao and Swaab 2011). In 1958, Royce and Sayers partially isolated a corticotropin-releasing hormone (CRH, also known as hypothalamic corticotropin-releasing factor (CRF)) that stimulates the secretion of adrenocorticotropic hormones (ACTH) from the pars distalis of the PG (McCann 1992; Menon et al. 2011). The complete purification and synthesis of CRH occurred about 2 decades later (Vale et al. 1981). ACTH, in turn, primarily activates the secretion of cortisol from the adrenal glands (Bao and Swaab 2011). Those hormones influence the stress response, and other related physiological mechanisms such as vascular tone and body metabolism (Hong et al. 2016). In the HPT axis, thyrotropin-releasing hormone (TRH) is released by the hypothalamus and stimulates thyroidstimulating hormone (TSH) release from the pars tuberalis (Menon et al. 2011). The thyroid then releases triiodothyronine (T3) and thyroxine (T4) hormones (Schroeder and Privalsky 2014), which regulate body temperature, metabolism, and heart rate. The PG also acts separately from those three neuroendocrine axes, as hormones released in the bloodstream might act directly on non-endocrine organs. The pars distalis produces growth hormones (GH) that have anabolic effects on the musculoskeletal system (Menon et al. 2011). The pars intermedia secretes betamelanocyte-stimulating hormone that affects skin pigmentation, and endorphins and enkephalins that act on the brain and immune system to inhibit pain (Menon et al. 2011). 


\section{Posterior PG}

Finally, the posterior PG releases oxytocin (OT), a hormone involved in uterine labor, lactation, orgasm, and social bonding (Musumeci et al. 2015); and vasopressin, the antidiuretic hormone $(\mathrm{ADH})$ that regulates the amount of water excreted by the kidneys and maintains water balance in the body (Menon et al. 2011). ADH can also act in coordination with CRH to promote ACTH secretion, and affects aggressiveness, social bonding, body temperature, and memory (Ishunina and Swaab 1999). The precursors of both OT and ADH are synthesized and almost fully processed in the magnocellular neurosecretory cells of the SON and PVN of the hypothalamus (Scheithauer et al. 1992). Indeed, unlike other endocrine structures, the posterior PG consists of the processes of mature neurons from the hypothalamus and can only stock and release hormones (Scheithauer et al. 1992). Those hormones are stored in the terminal of these unmyelinated projections, in secretory granules that accumulate inside large (1-50 micron diameter) "swellings" known as "Herring bodies" (Lechan and Toni, 2000; Scheithauer et al. 1992; Zimmerman and Robinson, 1976).

\section{Atypical PG size, especially during childhood and adolescence, is associated with abnormal function and behavior}

\section{Healthy development}

Under the influence of transcription factors that guide proliferation, apoptosis, and terminal gene activation, the anterior and posterior lobes of the PG undergo differentiation at the embryological stage from two distinct tissues, Rathke's pouch — constituted by ectoderm-and neuroectoderm, respectively (Bazina et al. 2007; de Moraes et al. 2012; Musumeci et al. 2015). The anterior gland begins functioning at the end of the first trimester of gestation, and the posterior gland at the end of fetal life (Amar and Weiss 2003). Characterizing the healthy PG development throughout childhood and adolescence remains extremely important, as they appear to be critical periods involved in most PGrelated disorders. For instance, only $4-6 \%$ of pediatric cases of PG tumors remain functionally silent, versus $33-50 \%$ in adults (Keil and Stratakis 2008). Moreover, recent work suggests that PG volume in early adolescence might predict subsequent psychiatric status (Zipursky et al. 2011). Typically, PG weight rapidly increases during childhood and adolescence, from $100 \mathrm{mg}$ at birth to $500-600 \mathrm{mg}$ in early adulthood (Amar and Weiss 2003). It measures approximately $10 \mathrm{~mm}$ in length, $10-15 \mathrm{~mm}$ in width, and $5 \mathrm{~mm}$ in height, although its dimensions in the three axes and thus volume vary throughout life (Amar and Weiss 2003). Some evidence suggests gonadal hormones can induce cell proliferation in the anterior lobe (Ronchetti et al. 2013), leading to PG growth. Autopsy data from individuals with no history of endocrine disorders have shown that PG volumes peak in the mid-20s to early 30s and then become smaller (Denk et al. 1999; Ju et al. 2010; Roppolo et al. 1983). The decrease after mid-life may be related to the decrease in androgenic activity or menopause, lower numbers of somatotropes, basophilic invasion of the neurohypophysis, compression by the adjacent carotid arteries, amyloid-beta and iron load (Castillo 2005), and formation of interstitial fibrosis in the anterior gland, especially in males (Everitt and Andrews 1983). These typical developmental trajectories based on histological data can be used as a reference for the validation of subsequent findings using MRI.

\section{Abnormal development}

PG size is associated with hormone secretion and can reflect endocrine disorders, such as Cushing's disease, gigantism, acromegaly, hyperprolactinemia, or diabetes insipidus. PG adenomas, particularly of the anterior PG, are a prime example of the relationship between PG size, hormone secretion and physical pathology. Tumors in the anterior PG can lead to ACTH hypersecretion, causing Cushing's disease; to GH hypersecretion, which causes gigantism and acromegaly; or to hyperprolactinemia, the most common endocrine disorder of the hypothalamic-pituitary axis (Bayrak et al. 2005; Fountas and Karavitaki 2017). Although studies on the volume of the posterior PG are rare, it is well known that $\mathrm{ADH}$ deficiency is seen in patients with diabetes insipidus, the symptoms of which are polyuria, frequent urination, and persistent thirst (Hong et al. 2016). The PG is also hypothesized to be involved in psychopathologies. This may be due to its role in the HPA axis which is often disrupted in psychopathologies (Scott and Dinan 1998). PG volume differs between males and females (Takano et al. 1999) suggesting it may be particularly useful to study PG volume growth trajectories in psychiatric disorders that typically present sex differences in their prevalence or symptom profile [for example, depression (Piccinelli and Wilkinson 2000) and schizophrenia (Abel et al. 2010)]. Mental disorders, however, are difficult to study due to their complex etiology and the need for well-powered studies on humans, particularly healthy youths who are not well represented in autopsy data. MRI allows in vivo, longitudinal, investigations with large numbers of human participants, and gives results comparable to those obtained in postmortem studies, which is the gold standard in neuroanatomy (Denk et al. 1999). With the development of increasingly accurate and reliable tools for MRI-based volumetric analyses, this technology is invaluable for the characterization of both normal and abnormal PG development. 


\section{Contributions of structural MRI}

\section{MRI studies of healthy development are validated by autopsy data}

\section{The effect of age}

In accordance with postmortem studies, MRI-based investigations have reported an increase of PG volume during adolescence, followed by a decrease in late adulthood. Log PG volume increases gradually in young children (Fink et al. 2005), and the existence of a growth spurt of PG volume during puberty, positively associated with circulating levels of PG and gonadal sex hormones (Peper et al. 2010) and paralleling the growth spurt of the human body itself, is well documented (MacMaster et al. 2007; Sari et al. 2014; Takano et al. 1999). The volume of the posterior PG increases less rapidly during puberty, suggesting that the anterior PG inhibits its growth (Takano et al. 1999). In adults over 50, the overall volume of the PG eventually decreases (Lurie et al. 1990). The posterior bright spot (PBS) decreases in size with age (Côté et al. 2014).

\section{Sex differences}

The change in PG volume with age is also moderated by sex. The most significant differences are seen during early adolescence, with girls displaying volumetric increases earlier than boys (Chen et al. 2004; Ganella et al. 2015; MacMaster et al. 2007). This is in line with the fact that girls experience puberty earlier than their male counterparts. Testosterone and estradiol levels were indeed reported to predict PG volume in males and pre-menarche girls independently of age (Wong et al. 2014). In late adolescence, Takano et al. (1999) and MacMaster et al. (2008) both reported a smaller effect of sex, but several other studies (Atmaca et al. 2009, 2010; Büschlen et al. 2011; Cousins et al. 2010; Gruner et al. 2012) observed a significant sexual dimorphism even in young adults. No sex difference was observed for older age groups (Eker et al. 2008). Importantly, as shown in Table 1, most groups either looked at whole PG volume, and only a few considered the anterior and posterior lobes separately (Fujisawa et al. 1987; Takano et al. 1999).

\section{Structural changes seen on MRI are associated with changes in function}

To better understand how PG volume relates to psychiatric status, several groups have attempted to characterize how it affects more basic phenotypes like HPA function (Axelson et al. 1992; Habets et al. 2012; Murray et al. 2016). This was motivated for instance by the abnormal levels of stress reactivity (hormonal response, self-reported emotional reactivity) observed in unaffected relatives of psychotic patients (Aiello et al. 2012). In adult patients with psychotic disorders, their siblings, and healthy controls, there was a positive correlation between PG volume and emotional stress reactivity, especially in the patients (Habets et al. 2012). Similarly, in other studies PG volume could predict subsequent HPA reactivity, as assessed, for instance, by the cortisol awakening response or the diurnal slope (Kaess et al. 2013, 2018). Other PG functions have been implicated in mental disorders, such as the HPG system and prolactin secretion in schizophrenia (Büschlen et al. 2011). The literature on pituitary involvement in psychopathologies suggests there might be at least two biologically distinct types of psychotic disorders, one characterized by small PGs and the other by larger PGs (Habets et al. 2012). This makes the case for the use of non-categorical inclusion criteria rather than only clinical labels in MRI studies.

\section{Inconsistencies in MRI studies of psychopathologies}

\section{Psychosis}

Unsurprisingly, a large number of studies report associations between the volume of either the whole or anterior PG and psychiatric status, especially in the context of psychotic disorders. To date, no consensus on the direction of the relationship has been reached. First-Episode Psychosis (FEP) groups were reported to have larger PGs than healthy controls in several (Atmaca 2014; Pariante et al. 2004; Takahashi et al. 2013) but not all (Gruner et al. 2012; Habets et al. 2012) studies, and so were their first-degree relatives (Aiello et al. 2012; Mondelli et al. 2008). One hypothesis is that larger PG volume is due to increased number and size of corticotropes and HPA hyperreactivity (Axelson et al. 1992; Pariante et al. 2004), although support for this hypothesis from animal studies is limited (Aguiar et al. 1997; Füchsl et al. 2013). HPA hyperreactivity, in turn, could affect the expression of genes critical in brain development like brain-derived neurotrophic factor (BDNF), especially during puberty, and lead to the onset of psychosis (Aiello et al. 2012; Borges et al. 2013). In that scenario, PG volume should be a strong predictor of transition to psychosis later in life. In fact, several studies found that individuals at clinical risk that transitioned to psychosis within the following years (Büschlen et al. 2011; Garner et al. 2005; Shah et al. 2015) had larger PGs, with a risk increase of $20 \%$ for every $10 \%$ increase in volume (Garner et al. 2005). A meta-analysis even concluded that the difference with healthy controls was significant in the transitioning ultrahigh-risk (UHR) group but not in the FEP group (Nordholm et al. 2013). Non-transitioning UHR reportedly had a smaller PG volume 


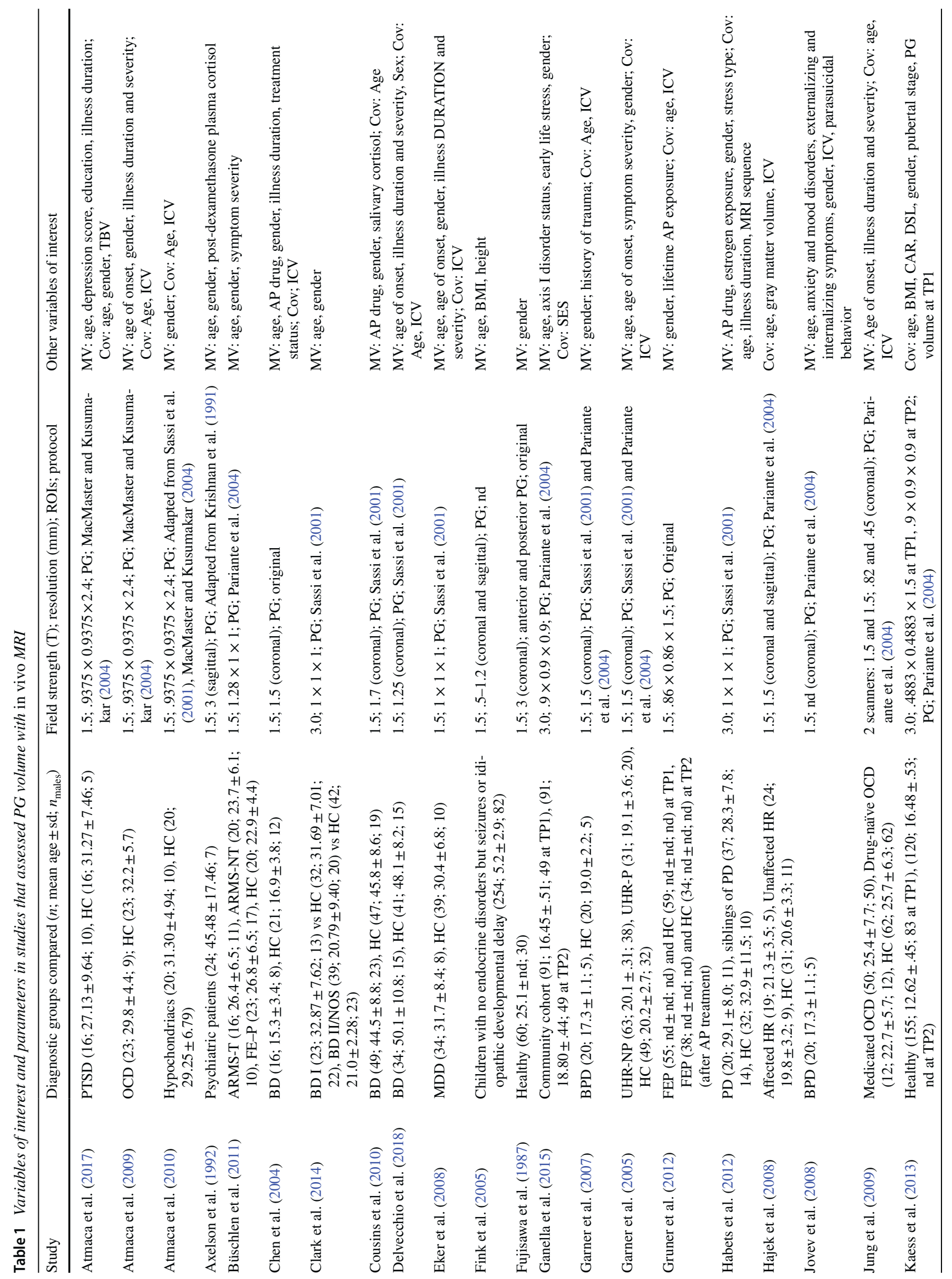




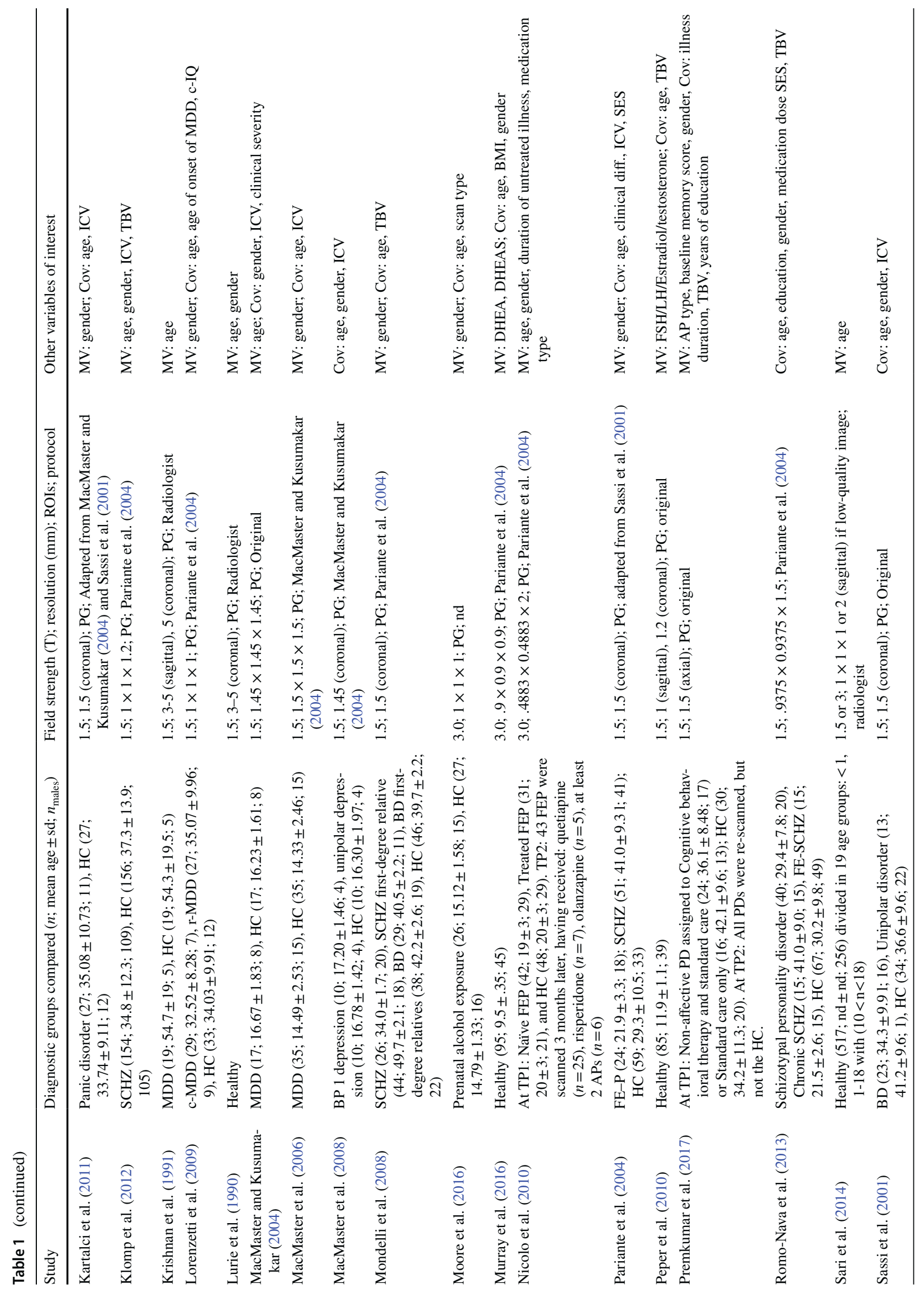




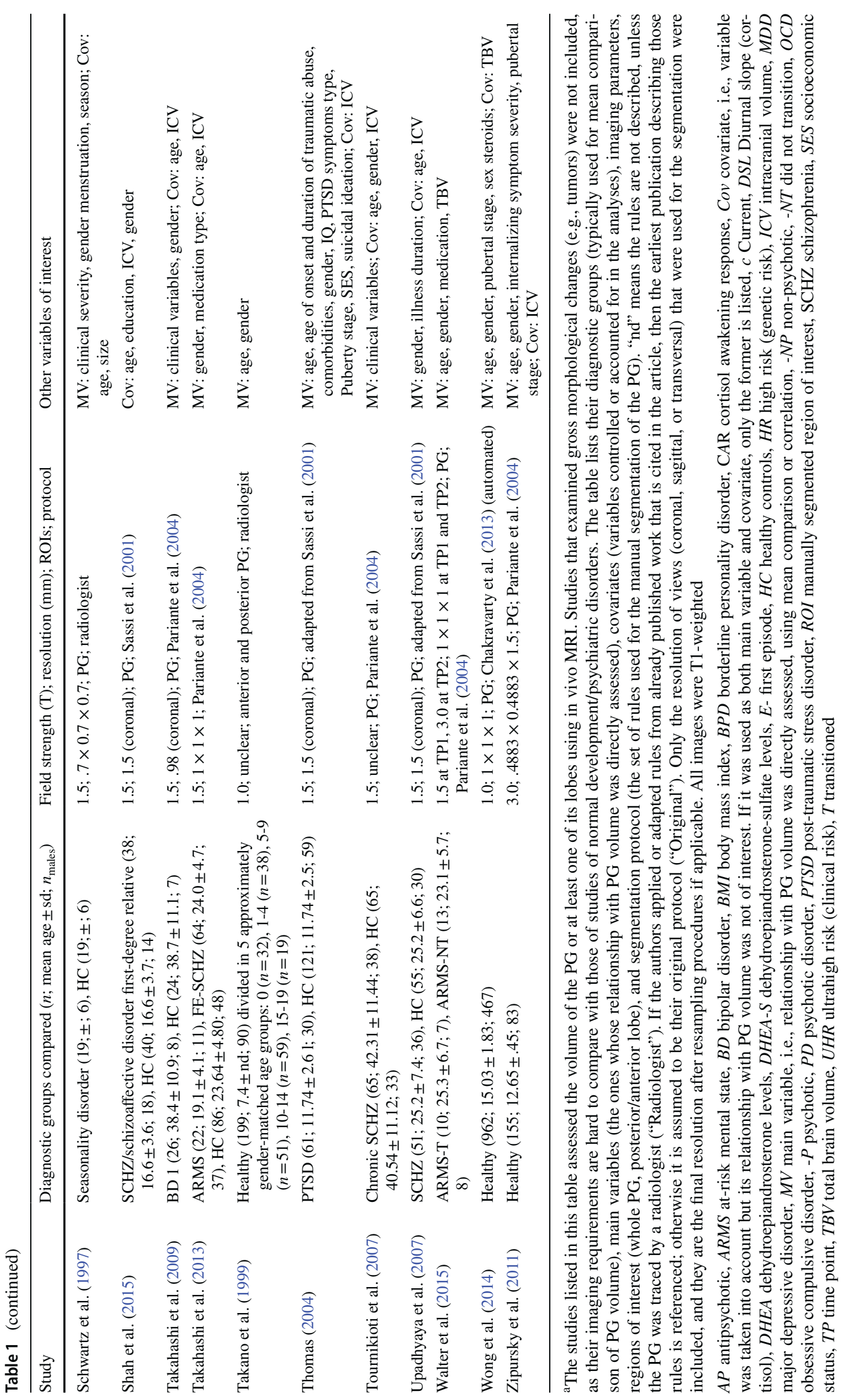


than healthy controls, suggesting the existence of a protective effect (Garner et al. 2005). In the longer term, however, chronic HPA activity is thought to strengthen the negative feedback control of the PG, leading to decreases in its volume (Delvecchio et al. 2018). For instance, schizophrenia patients seem to have smaller PGs than controls (Upadhyaya et al. 2007). Illness duration and PG volume were found to be inversely related, even in antipsychotic-naïve patients (Büschlen et al. 2011). In chronically ill patients, smaller PG volume detected with in vivo MRI may thus reflect HPA axis hypoactivity, as reported in schizophrenia (Romo-Nava et al. 2013; Tournikioti et al. 2007). Assessing structural trajectories of the PG using MRI could, therefore, help identify individuals at risk for psychotic disorders.

\section{Anxiety-, stress-, and trauma-related disorders}

The hypothesis that HPA reactivity is linked to PG volume in a time-dependent fashion is also supported by several findings in disorders associated with anxiety and stress abnormalities and early-life trauma. During late childhood, larger PG volumes were associated with more severe social anxiety (Murray et al. 2016). In a community cohort, maternal dysphoric behavior was associated with accelerated PG growth during adolescence, and girls were particularly vulnerable to the effects of childhood trauma (Ganella et al. 2015). Larger PG volumes in children exposed to high levels of childhood maltreatment have also been linked to lower cortisol awakening responses later in adolescence (Kaess et al. 2018). In contrast, adult patients with panic disorder (Kartalci et al. 2011), obsessive-compulsive disorder (Atmaca et al. 2009), hypochondriasis (Atmaca et al. 2010), and post-traumatic stress disorder (PTSD) (Atmaca et al. 2017) have been reported to have smaller PG volumes compared to age- and gender-matched healthy controls. Borderline personality disorder patients showed no volumetric changes overall (Garner et al. 2007), except adolescents with a history of parasuicidal behavior (Jovev et al. 2008), who had larger PG volumes. Finally, in contrast with Atmaca et al. (2017), Thomas (2004) found that PTSD patients only had larger PGs compared to controls during and after puberty, but not before. PG volume was also larger in patients that reported suicidal ideation (Thomas 2004).

\section{Mood disorders}

Although many studies looked at the relationship between bipolar disorder or depression and PG volume, reports of abnormal PG volume in patient groups could rarely be replicated (Delvecchio et al. 2017). Most groups found no significant difference in PG volume for either Major Depressive Disorder (MDD) (Eker et al. 2008; Klomp et al. 2012; Lorenzetti et al. 2009; Sassi et al. 2001) or bipolar disorder
(Clark et al. 2014; Chen et al. 2004; Mondelli et al. 2008) patient groups compared to healthy controls, even when they had enough power to control for illness burden or medication use. Of the studies that reported significant differences compared with healthy populations, most reported larger PGs in both bipolar (MacMaster et al. 2008; Pariante et al. 2005; Takahashi et al. 2009, 2010) and MDD patient groups (Krishnan et al. 1991; MacMaster et al. 2006; MacMaster and Kusumakar 2004; Pariante et al. 2005). In MDD, two longitudinal studies even concluded that PG volume in early adolescence predicted depressive symptom scores later in adolescence (Whittle et al. 2012; Zipursky et al. 2011). Interestingly, both Delvecchio et al. (2018) and Cousins et al. (2010) reported smaller pituitaries in female, but not male, bipolar patients, including in the absence of baseline HPA axis dysfunction (Cousins et al. 2010). Sassi et al. (2001) also found statistically smaller PGs in adult bipolar patients but could not replicate the results in children and adolescents (Chen et al. 2004). Genetic risk itself did not seem to have any effect (Hajek et al. 2008; Takahashi et al. 2010). Finally, reviews concluded that most investigations of PG volume in MDD and bipolar disorder were methodologically flawed (Delvecchio et al. 2017; Kessing et al. 2011).

\section{The methods: limitations and perspectives in MRI-based analysis}

\section{Inconsistencies in design and analyses may contribute to the lack of replicability}

\section{Population selection}

Meta-analyses revealed the high study bias (Arnone et al. 2012) and heterogeneity (Nordholm et al. 2013) in investigations of PG volume in psychopathologies. Contradictory results between imaging studies may be explained by several factors, not the least of which is the pooling of patients with different profiles, and unequal exposure to medication. For instance, prolactin-enhancing antipsychotics are associated with larger PG volume, whereas other antipsychotics (Borges et al. 2013; Nicolo et al. 2010) and cognitive behavioral therapy (Premkumar et al. 2017) may reduce PG volume, complicating the study of psychotic disorders on PG volumes. Similar effects of medication have been reported in obsessive-compulsive disorder (Jung et al. 2009) and drug abuse (Lorenzetti et al. 2010); contraceptive use should be controlled for as well (Grams et al. 2010; Nordholm et al. 2013). Moreover, clinical definitions of patient groups based on the Diagnostic and Statistical Manual of Mental Disorders may be too rigid for imaging studies, especially for disorders such as schizophrenia, and a solution could be to move towards more functionally relevant definitions (e.g.,: 
HPA reactivity, prolactin secretion, clinical scores). It is also critical to account for population (Sahni et al. 2006) and gender (Nordholm et al. 2013; Delvecchio et al. 2018) differences.

\section{MRI acquisition parameters}

Furthermore, although fast-spin, T1-weighted sequence and the use of multi-coil acquisition result in fairly good images of the PG, acquisition protocols may still be further improved upon. Increases in magnetic field strength have greatly helped with the diagnosis of PG tumors in clinical settings (BouAyache and Delman 2016), suggesting that much could be gained from using 3T scanners (Shah et al. 2012), high-resolution data ( $<1 \mathrm{~mm}^{3}$ voxel size), and resampling techniques. The latter can reduce anisotropy, which introduces sampling bias and partial volume effects (Amaral et al. 2016). Partial volume effects and inherent anatomical variability are easily confused with PG adenomas (Ouyang et al. 2011; Pantalone et al. 2015). The acquisition of T2-weighted images is also desirable, as in high-resolution T2-weighted images of the rat, the intermediate lobe can be identified as a hyperintense signal separating the isointense anterior and slightly hypointense posterior lobes (Naidich and Russell 1999; Theunissen et al. 2010). Moreover, the visualization of the PS is better on T2, where it has a lower signal than the surrounding cerebrospinal fluid (Delman 2009; Satogami et al. 2010). Although the PG is best seen on coronal slices, 3D volumetry using all views is more accurate than the geometric method, and 3D sequences should be preferred (Renz et al. 2011). In earlier studies, statistical analyses did not routinely account for differences in intracranial volume (Cousins et al. 2010; Fink et al. 2005), which could lead to effects of whole brain volume differences erroneously being attributed to effects of PG volume differences. Overall, comparison of MRI results has been hindered by the lack of a standardized protocol for the MRI acquisition, image processing, as well as a detailed manual delineation of the PG.

\section{Manual segmentation needs to be biologically and anatomically informed}

\section{Issues in the current methodology for segmenting the PG}

The gold standard in MRI-based analysis is histologically informed manual segmentation. Until now, the vast majority of imaging studies on the PG defined its boundaries in roughly the same terms (cavernous sinuses laterally, sphenoid sinus inferiorly, and diaphragm sellae superiorly) (Atmaca et al. 2009; Axelson et al. 1992; Sassi et al. 2001; Thomas 2004; Tournikioti et al. 2007), but did not describe the appearance of those landmarks on MRI. Given the small size of the PG, differences in segmenting style are thus likely to heavily impact inter-rater reliability as assessed by voxel overlap (Dice Kappa scores) rather than volumetric correlation (intraclass correlation) or variance (coefficient of variation). Moreover, most groups traced the PG as one structure. This is unfortunate because the functionally distinct anterior and posterior lobes are likely not equally involved in the pathologies of interest and segmenting them separately could reduce noise in volumetric analyses.

\section{Accounting for the PBS}

A new definition of the posterior lobe, which tracers typically assimilate to the PBS, is thus needed. Two studies have highlighted the importance of having distinct segmentation rules for the PBS and the posterior PG, partly because the former is not a reliable landmark and needs to be further characterized (Côté et al. 2014). Indeed, the PBS, first attributed to the presence of fat deposits (Chen and Kucharczyk 1989; Nishimura et al. 1986), is now thought to reflect the levels of mature ADH levels (Côté et al. 2014; Fujisawa et al. 1987). Its intensity thus varies with hydration state, as shown experimentally in animals (Lee et al. 2001). It also varies with gender (Yamamoto et al. 2013). Patients with diabetes insipidus - caused by ADH deficiency_lack a PBS in $25-100 \%$ of cases, while other conditions are characterized by an ectopic PBS (Côté et al. 2014). Therefore, it is not uncommon for the PBS to be either absent or displaced on MRI, even in the healthy population (Anderson et al. 1999; Côté et al. 2014; Terano et al. 1996), and segmentations of the posterior PG should not be intensity dependent if possible.

\section{The PS}

The appearance, including volume, depth and length, of the normal PS has been described on T1- and T2-weighted MRI images acquired on a 3T (Satogami et al. 2010) and a 1.5T scanner (Raveendranath et al. 2019). Other groups highlighted the importance of assessing the width of the infundibular recess as it may affect other parameters such as PS thickness (Raveendranath et al. 2019). One can delineate the infundibular recess from the PS better on high-resolution images [e.g., . $3 \mathrm{~mm}$ isotropic (Tullo et al. 2018)] as shown in Fig. 2, but most MRIs will not allow for the distinct segmentation of the neuronal or vascular component.

\section{Future perspectives in MRI-based analyses of the PG}

In conclusion, segmenting difficulties arise from the large inter-individual variability of both lobes (Fink et al. 2005; Fujisawa et al. 1987). This highlights the need for the 


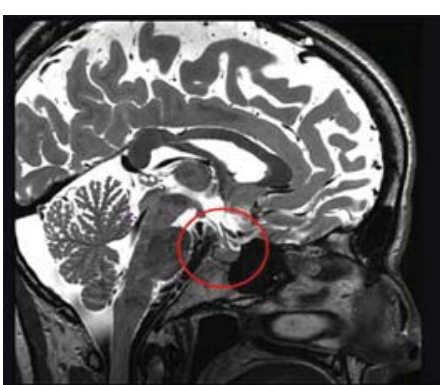

a

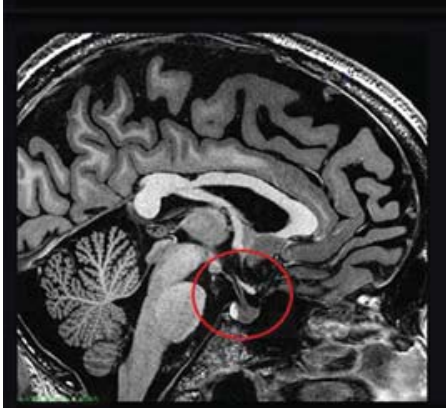

d

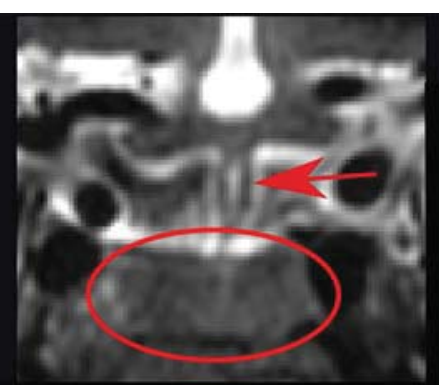

b

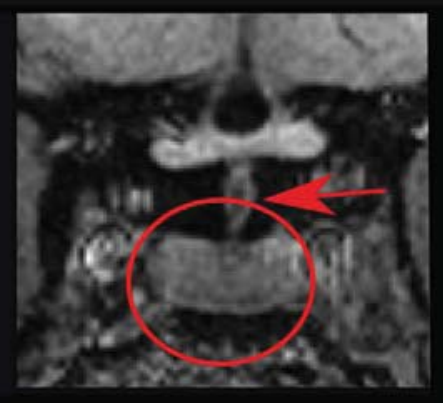

e

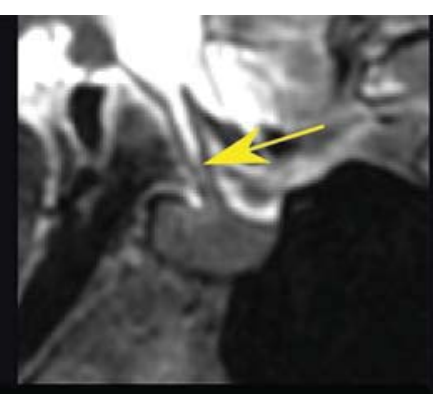

c
Fig. 2 Appearance of the PG and PS on 3T T2 (a-c) and T1 (d-f) weighted MRI with a voxel resolution of $.3 \mathrm{~mm}$ isotropic (Tullo et al. 2018). a, d Gross localization of the PG (red circle) on the sagittal view. b, e Coronal view of the PG (red circle) and PS (red arrow). The cavernous sinuses and the optic chiasm can be identified lateral

objectification of baseline intensity (including intensity normalization during image processing) and a better description of the landmarks used. Future studies should also explore the diversity of signals that can be acquired with structural MRI, which will hopefully lead to a redefinition of the posterior lobe. Segmentation rules for the posterior lobe that assimilate it to the PBS are particularly susceptible to the observer's biased perception of intensity and based on a false equivalency. The creation of better segmentation protocols should be facilitated by the increased use of high-resolution images in research and clinical settings and the standardization of image processing techniques. Ultimately, automated segmentation should aim to allow the rapid assessment of the PG on large datasets. Moreover, automated approaches have been successful in identifying gross volumetric changes across adolescence (Wong et al. 2014) and in PG adenomas (Egger et al. 2012), and the application of automated approaches in hippocampal subfields suggests they can be used for more refined analyses (Pipitone et al. 2014). Sophisticated techniques such as deformation-based and voxelbased morphometry can then be applied to large datasets using flexible, automated toolkits designed specifically for longitudinal investigations (Lerch et al. 2017). to and above the PG, respectively. c, f Zoomed-in sagittal view. On the T1, the PBS can be seen (green arrow). The PS is comprised of a vascular and a neuronal component, and only the latter extends beyond the infundibular recess (yellow arrow), towards the optic chiasm (Satogami et al. 2010)

\section{Conclusion}

In summary, the PG is an important neuroendocrine structure that changes across development and is implicated in a number of physical and psychological conditions. In spite of ample research suggesting that structural changes of the PG can be identified in psychopathologies, our knowledge of the trajectory of those changes-across time as well as between and within clinical conditions-is hampered by design inconsistencies in terms of population selection, MRI acquisition parameters, and PG definition. In this review, we proposed to sort participants based on basic functional measures (e.g., stress reactivity) as well as stricter exclusion criteria (e.g., medication intake); acquisition of both 3D T1- and T2-weighted images, ideally at 3.0 T; the use of super-sampling techniques to obtain better voxel resolution $(<1 \mathrm{~mm})$, if possible isotropic; and the separate delineation of the anterior and posterior PGs, accounting for their functional and structural differences in development.

Acknowledgements Sherri Lee Jones is funded by a post-doctoral fellowship from the Fonds de recherche du Québec-Santé. Special thanks to the lab of Dr. M. Mallar Chakravarty at the Douglas Mental Health 
University Institute, McGill University, for thoughtful discussions regarding technicalities and limitations of structural MRI, particularly for small structures such as the pituitary gland. Figure 2 was generated from high-resolution atlases made available open source by Dr. M. Mallar Chakravarty (Douglas Institute, McGill University, Montreal, QC, Canada).

\section{Compliance with ethical standards}

Conflict of interest The authors declare that they have no conflicts of interest.

\section{References}

Abel KM, Drake R, Goldstein JM (2010) Sex differences in schizophrenia. Int Rev Psychiatry 22(5):417-428. https://doi. org/10.3109/09540261.2010.515205

Aguiar CE, Cadore LP, Padoin MJ et al (1997) Aversive stimulation during the stress-hyporesponsive period does not affect the number of corticotroph cells in neonatal male rats. Braz J Med Biol Res 30(12):1463-1466. https://doi.org/10.1590/S0100-879X1 997001200013

Aiello G, Horowitz M, Hepgul N et al (2012) Stress abnormalities in individuals at risk for psychosis: a review of studies in subjects with familial risk or with at-risk mental state. Psychoneuroendocrinology 37(10):1600-1613. https://doi.org/10.1016/j.psyne uen.2012.05.003

Amar AP, Weiss MH (2003) Pituitary anatomy and physiology. Neurosurg Clin N Am 14(1):11-23. https://doi.org/10.1016/S1042 $-3680(02) 00017-7$

Amaral RSC, Park MTM, Devenyi GA et al (2016) Manual segmentation of the fornix, fimbria, and alveus on high-resolution 3T MRI: application via fully-automated mapping of the human memory circuit white and grey matter in healthy and pathological aging. NeuroImage 170:132-150. https://doi.org/10.1016/j.neuroimage .2016 .10 .027

Anderson JR, Antoun N, Burnet N et al (1999) Neurology of the pituitary gland. J Neurol Neurosurg Psychiatry 66:703-721. https:// doi.org/10.1136/jnnp.66.6.703

Arnone D, McIntosh AM, Ebmeier KP et al (2012) Magnetic resonance imaging studies in unipolar depression: systematic review and meta-regression analyses. Eur Neuropsychopharmacol 22(1):116. https://doi.org/10.1016/j.euroneuro.2011.05.003

Atmaca M (2014) Pituitary gland in psychiatric disorders: a review of neuroimaging findings. Pituitary 17(4):392-397. https://doi. org/10.1007/s11102-013-0512-2

Atmaca M, Yildirim H, Ozler S et al (2009) Smaller pituitary volume in adult patients with obsessive-compulsive disorder. Psychiatry Clin Neurosci 63(4):516-520. https://doi.org/10.111 1/j.1440-1819.2009.01981.x

Atmaca M, Yildirim H, Sec S, Kayali A (2010) Pituitary volumes in hypochondriac patients. Prog Neuropsychopharmacol Biol Psychiatry 34(2):344-347. https://doi.org/10.1016/J.PNPBP .2009 .12 .012

Atmaca M, Ozer O, Korkmaz S et al (2017) Evidence for the changes of pituitary volumes in patients with post-traumatic stress disorder. Psychiatry Res Neuroimaging 260:49-52. https://doi. org/10.1016/j.pscychresns.2016.12.004

Axelson DA, Doraiswamy PM, Boyko OB et al (1992) In vivo assessment of pituitary volume with MRI and systematic stereology: relationship to dexamethasone suppression test results in patients. Psychiatry Res 44(1):63-70. https://doi.org/10.1016/01651781(92)90070-J
Bao AM, Swaab DF (2011) Sexual differentiation of the human brain: relation to gender identity, sexual orientation and neuropsychiatric disorders. Front Neuroendocrinol 32(2):214-226. https://doi.org/10.1016/j.yfrne.2011.02.007

Bayrak A, Saadat P, Mor E et al (2005) Pituitary imaging is indicated for the evaluation of hyperprolactinemia. Fertil Steril 84(1):181-185. https://doi.org/10.1016/j.fertnstert .2005.01.102

Bazina M, Stefanović V, Božanić D, Saraga-Babić M (2007) Ultrastructural and immunohistochemical characteristics of developing human pituitary gland. Acta Histochem 109(5):366-376. https:// doi.org/10.1016/j.acthis.2007.03.005

Ben-Shlomo A, Shlomo M (2017) Hypothalamic regulation of anterior pituitary function. In Melmed S (ed) The pituitary, 4th ed, pp 23-45

Borges S, Gayer-Anderson C, Mondelli V (2013) A systematic review of the activity of the hypothalamic-pituitary-adrenal axis in first episode psychosis. Psychoneuroendocrinology. https://doi. org/10.1016/j.psyneuen.2012.12.025

Bou-Ayache JM, Delman BN (2016) Advances in imaging of the pediatric pituitary gland. Endocrinol Metab Clin North Am. https:// doi.org/10.1016/j.ecl.2016.02.004

Büschlen J, Berger GE, Borgwardt SJ et al (2011) Pituitary volume increase during emerging psychosis. Schizophr Res 125(1):4148. https://doi.org/10.1016/j.schres.2010.09.022

Castaneda Cortés DC, Langlois VS, Fernandino JI (2014) Crossover of the hypothalamic pituitary-adrenal/interrenal, -thyroid, and -gonadal axes in testicular development. Front Endocrinol 5(139):1-11. https://doi.org/10.3389/fendo.2014.00139

Castillo M (2005) Pituitary gland: development, normal appearances, and MRI protocols. Top Magn Reson Imaging 16(4):259-268. https://doi.org/10.1097/01.rmr.0000224682.91253.15

Chakravarty MM, Steadman P, van Eede MC et al (2013) Performing label-fusion-based segmentation using multiple automatically generated templates. Human Brain Mapp 34(10):2635-2654. https://doi.org/10.1002/hbm.22092

Chen JC, Kucharczyk W (1989) Hypothalamic-pituitary region: MRI. Bailliere's Clin Endocrinol Metab 3(1):73-87. http://www.ncbi. nlm.nih.gov/pubmed/2679525

Chen HH, Nicoletti M, Sanches M et al (2004) Normal pituitary volumes in children and adolescents with bipolar disorder: a MRI study. Depress Anxiety 20(4):182-186. https://doi.org/10.1002/ da. 20044

Chrousos GP, Gold PW (1992) The concepts of stress and stress system disorders: overview of physical and behavioral homeostasis. JAMA 267(9):1244-1252. https://doi.org/10.1001/ jama.1992.03480090092034

Clark IA, Mackay CE, Goodwin GM (2014) Pituitary gland volumes in bipolar disorder. J Affect Disord 169:197-202. https://doi. org/10.1016/j.jad.2014.08.022

Côté M, Salzman KL, Sorour M, Couldwell WT (2014) Normal dimensions of the posterior pituitary bright spot on MRI. J Neurosurg 120(2):357-362. https://doi.org/10.3171/2013.11.JNS131320

Cousins DA, Brian Moore P, Watson S, Harrison L et al (2010) Pituitary volume and third ventricle width in euthymic patients with bipolar disorder. Psychoneuroendocrinology 35(7):1074-1081. https://doi.org/10.1016/j.psyneuen.2010.01.008

Dada MO, Campbell GT, Blake CA (1984) The localization of gonadotrophs in normal adult male and female rats. Endocrinology 114(2):397-406. https://doi.org/10.1677/joe.0.1010087

Davis SW, Mortensen AH, Camper SA (2011) Birthdating studies reshape models for pituitary gland cell specification. Dev Biol 352(2):215-227. https://doi.org/10.1016/j.ydbio.2011.01.010

de Moraes DC, Vaisman M, Conceiçao FL, Ortiga-Carvalho TM (2012) Pituitary development: a complex, temporal regulated 
process dependent on specific transcriptional factors. J Endocrinol. https://doi.org/10.1530/JOE-12-0229

Delman BN (2009) Imaging of pediatric pituitary abnormalities. Endocrinol Metab Clin N Am. https://doi.org/10.1016/j. ecl.2009.09.001

Delvecchio G, Altamura A, Soares J, Brambilla P (2017) Pituitary gland in bipolar disorder and major depression: evidence from structural MRI studies. J Affect Disord 218:446-450. https://doi. org/10.1016/j.jad.2017.03.066

Delvecchio G, Mandolini GM, Perlini C, Barillari M, Marinelli V, Ruggeri M, Altamura AC, Bellani M, Brambilla P (2018) Pituitary gland shrinkage in bipolar disorder: the role of gender. Compr Psychiatry 82:95-99. https://doi.org/10.1016/j.compp sych.2018.01.014

Doraiswamy PM, Krishnan KR, Boyko OB et al (1991) Pituitary abnormalities in eating disorders: further evidence from MRI studies. Prog Neuropsychopharmacol Biol Psychiatry 15(3):351-356. https://doi.org/10.1016/0278-5846(91)90066-a

Eagle RC, Tortonese DJ (2000) Characterization and distribution of gonadotrophs in the pars distalis and pars tuberalis of the equine pituitary gland during the estrous cycle and seasonal anestrus. Biol Reprod 63(3):826-832

Egger J, Kapur T, Nimsky C, Kikinis R (2012) Pituitary adenoma volumetry with 3D Slicer. PLoS One 7(12):e51788. https://doi. org/10.1371/journal.pone.0051788

Eker C, Ovali GY, Ozan E et al (2008) No pituitary gland volume change in medication-free depressed patients. Prog Neuropsychopharmacol Biol Psychiatry 32(7):1628-1632. https://doi. org/10.1016/j.pnpbp.2008.05.023

Everitt AV, Andrews GR (1983) Hypothalamo-hypophyseal-adrenal axis. In: Platt D (ed) Geriatrics, 2nd edn. Springer, Berlin, pp 88-101. https://doi.org/10.1007/978-3-642-68217-94

Fekete C, Lechan RM (2014) Central regulation of hypothalamicpituitary-thyroid axis under physiological and pathophysiological conditions. Endocr Rev. https://doi.org/10.1210/er.2013-1087

Fink AM, Vidmar S, Kumbla S et al (2005) Age-Related pituitary volumes in prepubertal children with normal endocrine function: volumetric MR data. J Clin Endocrinol Metabol 90(6):32743278. https://doi.org/10.1210/jc.2004-1558

Fountas A, Karavitaki N (2017) Diagnosis of pituitary disease. Medicine 45(8):464-469. https://doi.org/10.1016/j.mpmed .2017.05.008

Füchsl AM, Langgartner D, Reber SO (2013) Mechanisms underlying the increased plasma ACTH levels in chronic psychosocially stressed male mice. PLoS ONE 8(12):e84161. https://doi. org/10.1371/journal.pone.0084161

Fujisawa I, Asato R, Nishimura K et al (1987) Anterior and posterior lobes of the pituitary gland: assessment by $1.5 \mathrm{~T}$ MRI. J Comput Assist Tomogr 11(2):214-220. https://doi.org/10.1097/00004 728-198703000-00003

Ganella DE, Allen NB, Simmons JG et al (2015) Early life stress alters pituitary growth during adolescence-a longitudinal study. Psychoneuroendocrinology 53:185-194. https://doi.org/10.1016/j. psyneuen.2015.01.005

Garner B, Pariante CM, Wood SJ et al (2005) Pituitary volume predicts future transition to psychosis in individuals at ultra-high risk of developing psychosis. Biol Psychiatry 58(5):417-423. https:// doi.org/10.1016/j.biopsych.2005.04.018

Garner B, Chanen AM, Phillips L et al (2007) Pituitary volume in teenagers with first-presentation borderline personality disorder. Psychiatry Res Neuroimaging 156(3):257-261. https://doi. org/10.1016/j.pscychresns.2007.05.001

Grams AE, Gempt J, Stahl A, Förschler A (2010) Female pituitary size in relation to age and hormonal factors. Neuroendocrinology 92(2):128-132. https://doi.org/10.1159/000314196
Gruner P, Christian C, Robinson DG et al (2012) Pituitary volume in first-episode schizophrenia. Psychiatry Res Neuroimaging 203(1):100-102. https://doi.org/10.1016/j.pscychresn s.2011.09.017

Denk CC, Onderoğlu S, Ilgi S, Gürcan, F (1999) Height of normal pituitary gland on MRI: differences between age groups and sexes. Okajimas Folia Anat Jpn 76(2-3):81-87. http://www. ncbi.nlm.nih.gov/pubmed/10502959

Habets P, Collip D, Myin-Germeys I et al (2012) Pituitary volume, stress reactivity and genetic risk for psychotic disorder. Psychol Med 42(7):1523-1533. https://doi.org/10.1017/S0033 291711002728

Hajek T, Gunde E, Bernier D et al (2008) Pituitary volumes in relatives of bipolar patients. Eur Arch Psychiatry Clin Neurosci 258(6):357-362. https://doi.org/10.1007/s00406-008-0804-0

Hong GK, Payne SC, Jane JA (2016) Anatomy, physiology, and laboratory evaluation of the pituitary gland. Otolaryngol Clin North Am 49(1):21-32. https://doi.org/10.1016/j.otc.2015.09.002

Ishunina TA, Swaab DF (1999) Vasopressin and oxytocin neurons of the human supraoptic and paraventricular nucleus; size changes in relation to age and sex. J Clin Endocrinol Metab 84(12):4637-4644. https://doi.org/10.1210/jcem.84.12.6187

Jovev M, Garner B, Phillips L et al (2008) An MRI study of pituitary volume and parasuicidal behavior in teenagers with firstpresentation borderline personality disorder. Psychiatry Res: Neuroimaging 162(3):273-277. https://doi.org/10.1016/j.psych resns.2007.12.003

Ju KS, Bae HG, Park HK et al (2010) Morphometric study of the korean adult pituitary glands and the diaphragma sellae. J Korean Neurosurg Soc 47(1):42-47. https://doi.org/10.3340/ jkns.2010.47.1.42

Jung MH, Huh MJ, Kang DH et al (2009) Volumetric differences in the pituitary between drug-naïve and medicated male patients with obsessive-compulsive disorder. Prog Neuropsychopharmacol Biol Psychiatry 33(4):605-609. https://doi. org/10.1016/j.pnpbp.2009.02.017

Kaess M, Simmons JG, Whittle S et al (2013) Sex-specific prediction of hypothalamic-pituitary-adrenal axis activity by pituitary volume during adolescence: a longitudinal study from 12 to 17 years of age. Psychoneuroendocrinology 38(11):26942704. https://doi.org/10.1016/j.psyneuen.2013.06.028

Kaess M, Whittle S, O'Brien-Simpson L et al (2018) Childhood maltreatment, pituitary volume and adolescent hypothalamicpituitary-adrenal axis-evidence for a maltreatment-related attenuation. Psychoneuroendocrinology 98:39-45. https://doi. org/10.1016/j.psyneuen.2018.08.004

Kartalci S, Dogan M, Unal S et al (2011) Pituitary volume in patients with panic disorder. Prog Neuropsychopharmacol Biol Psychiatry 35(1):203-207. https://doi.org/10.1016/j.pnpbp 2010.11.005

Keil MF, Stratakis CA (2008) Pituitary tumors in childhood: update of diagnosis, treatment and molecular genetics. Expert Rev Neurother 8(4):563-574. https://doi.org/10.1586/14737 175.8.4.563

Kessing LV, Willer IS, Knorr U (2011) Volume of the adrenal and pituitary glands in depression. Psychoneuroendocrinology 36(1):19-27. https://doi.org/10.1016/j.psyneuen.2010.05.007

Kiecker C (2017) The origins of the circumventricular organs. J Anat. https://doi.org/10.1111/joa.12771

Klomp A, Koolschijn PCMP, Hulshoff Pol HE et al (2012) Hypothalamus and pituitary volume in schizophrenia: a structural MRI study. Int J Neuropsychopharmacol 15(2):281-288. https://doi. org/10.1017/S1461145711000794

Krishnan KRR, Doraiswamy PM, Lurie SN et al (1991) Pituitary size in depression. J Clin Endocrinol Metab 72(2):256-259. https:// doi.org/10.1210/jcem-72-2-256 
Laios K, Androutsos G, Piagkou M, Moschos MM (2017) Hypophysis. From outgrowth, to ocular disorder to pituitary gland. Hormones. https://doi.org/10.14310/horm.2002.1726

Le Tissier PR, Hodson DJ, Lafont C et al (2012) Anterior pituitary cell networks. Front Neuroendocrinol 33(3):252-266. https://doi. org/10.1016/j.yfrne.2012.08.002

Lechan RM, Toni R (2000) Functional anatomy of the hypothalamus and pituitary. Endotext 4. http://www.ncbi.nlm.nih.gov/pubme $\mathrm{d} / 25905349$

Lee MH, Choi HY, Sung YA, Lee JK (2001) High signal intensity of the posterior pituitary gland on T1-weighted MR images. Correlation with plasma vasopressin concentration to water deprivation. Acta Radiol 42(2):129-134. https://doi.org/10.1080/02841 8501127346567

Lerch JP, van der Kouwe AJW, Raznahan A et al (2017) Studying neuroanatomy using MRI. Nat Neurosci 20(3):314-326. https:// doi.org/10.1038/nn.4501

Lorenzetti V, Allen NB, Fornito A et al (2009) Pituitary gland volume in currently depressed and remitted depressed patients. Psychiatry Res Neuroimaging 172(1):55-60. https://doi.org/10.1016/j. pscychresns.2008.06.006

Lorenzetti V, Lubman DI, Velakoulis D, Yücel M (2010) Pituitary gland volume among heroin users stabilised on substitution pharmacotherapy. Drug Alcohol Depend 110(1-2):164-166. https:// doi.org/10.1016/j.drugalcdep.2010.02.012

Lurie SN, Doraiswamy PM, Husain MM et al (1990) In vivo assessment of pituitary gland volume with MRI: the effect of age. J Clin Endocrinol Metabol 71(2):505-508. https://doi.org/10.1210/ jcem-71-2-505

MacMaster FP, Kusumakar V (2004) MRI study of the pituitary gland in adolescent depression. J Psychiatric Res 38(3):231-236. https ://doi.org/10.1016/j.jpsychires.2003.11.001

MacMaster FP, Russell A, Mirza Y et al (2006) Pituitary volume in treatment-naïve pediatric major depressive disorder. Biol Psychiatry 60(8):862-866. https://doi.org/10.1016/j.biops ych.2006.04.013

MacMaster FP, Keshavan M, Mirza Y et al (2007) Development and sexual dimorphism of the pituitary gland. Life Sci 80(10):940 944. https://doi.org/10.1016/j.lfs.2006.11.040

MacMaster FP, Leslie R, Rosenberg DR, Kusumakar V (2008) Pituitary gland volume in adolescent and young adult bipolar and unipolar depression. Bipolar Disord 10(1):101-104. https://doi. org/10.1111/j.1399-5618.2008.00476.x

McCartney CR***, Marshall, JC (2019) Endocrinology of reproduction. In Strauss III JF (ed) Yen and Jaffe's Reproductive Endocrinology, 8th ed: 1-24.e8

McCann SM (1992) An introduction to neuroendocrinology: basic principles and historical considerations. In Nemeroff (ed) Neuroendocrinology, $2^{\text {nd }}$ ed: 618. CRC Press, Boca Raton

Menon R, Murphy PG, Lindley AM (2011) Anaesthesia and pituitary disease. CEACCP 11(4):133-137. https://doi.org/10.1093/bjace accp/mkr014

Mondelli V, Dazzan P, Gabilondo A et al (2008) Pituitary volume in unaffected relatives of patients with schizophrenia and bipolar disorder. Psychoneuroendocrinology 33(7):1004-1012. https:// doi.org/10.1016/j.psyneuen.2008.05.010

Moore CR, Price D (1932) Gonad hormone functions, and the reciprocal influence between gonads and hypophysis with its bearing on the problem of sex hormone antagonism. Am J Anat 50(1):1371. https://doi.org/10.1002/aja.1000500103

Moore EM, Infante MA, Migliorini R et al (2016) Pituitary lacks sexual dimorphism and displays reduced signal intensity on T1-weighted MRI in adolescents with histories of heavy prenatal alcohol exposure. Neurotoxicol Teratol 57:106-111. https://doi. org/10.1016/j.ntt.2016.09.001
Morgan PJ, Williams LM (1996) The pars tubelaris of the pituitary: a gateway for neuroendocrine output. Rev Reprod 1(3):153-161. https://doi.org/10.1530/revreprod/1.3.153

Murray CR, Simmons JG, Allen NB et al (2016) Associations between dehydroepiandrosterone levels, pituitary volume, and social anxiety in children. Psychoneuroendocrinology 64:31-39. https://doi. org/10.1016/j.psyneuen.2015.11.004

Musumeci G, Castorina S, Castrogiovanni P et al (2015) A journey through the pituitary gland: development, structure and function, with emphasis on embryo-foetal and later development. Acta Histochem 117(4-5):355-366. https://doi.org/10.1016/j.acthi s.2015.02.008

Naidich MJ, Russell EJ (1999) Current approaches to imaging of the sellar region and pituitary. Endocrinol Metabol Clin North Am. https://doi.org/10.1016/S0889-8529(05)70057-8

Nicolo JP, Berger GE, Garner BA et al (2010) The effect of atypical antipsychotics on pituitary gland volume in patients with firstepisode psychosis: A longitudinal MRI study. Schizophrenia Res 116(1):49-54. https://doi.org/10.1016/j.schres.2009.10.005

Nishimura K, Fujisawa I, Togashi K et al (1986) Posterior lobe of the pituitary: identification by lack of chemical shift artifact in MRI. J Comp Assist Tomogr 10(6):899-902. https://doi. org/10.1097/00004728-198611000-00001

Nordholm D, Krogh J, Mondelli V et al (2013) Pituitary gland volume in patients with schizophrenia, subjects at ultra high-risk of developing psychosis and healthy controls: a systematic review and meta-analysis. Psychoneuroendocrinology 38(11):23942404. https://doi.org/10.1016/j.psyneuen.2013.06.030

Ouyang T, Rothfus WE, Ng JM, Challinor SM (2011) Imaging of the pituitary. Radiol Clin North Am 49(3):549-571. https://doi. org/10.1016/j.rcl.2011.02.012

Pantalone KM, Jones SE, Weil RJ et al (2015) Atlas of pituitary imaging. In Pantalone (ed) MRI Atlas of pituitary pathology (1st edn), pp 1-50. Elsevier. https://doi.org/10.1016/B978-0-12-80257 7-2.00001-3

Pariante CM, Vassilopoulou K, Velakoulis D et al (2004) Pituitary volume in psychosis. Br J Psychiatry 185:5-10. https://doi. org/10.1192/bjp.185.1.5

Pariante CM, Dazzan P, Danese A et al (2005) Increased pituitary volume in antipsychotic-free and antipsychotic-treated patients of the AEsop first-onset psychosis study. Neuropsychopharmacology 30(10):1923-1931. https://doi.org/10.1038/sj.npp.1300766

Peper JS, Brouwer RM, van Leeuwen M et al (2010) HPG-axis hormones during puberty: a study on the association with hypothalamic and pituitary volumes. Psychoneuroendocrinology 35(1):133-140. https://doi.org/10.1016/j.psyneuen.2009.05.025

Piccinelli M, Wilkinson G (2000) Gender differences in depression. Critical review. Br J Psychiatry 177:486-492. https://doi. org/10.1192/bjp.177.6.486

Pipitone J, Park MTM, Winterburn J et al (2014) Multi-atlas segmentation of the whole hippocampus and subfields using multiple automatically generated templates. NeuroImage 101:494-512. https://doi.org/10.1016/j.neuroimage.2014.04.054

Premkumar P, Bream D, Sapara A et al (2017) Pituitary volume reduction in schizophrenia following cognitive behavioural therapy. Schizophrenia Res 192:416-422. https://doi.org/10.1016/j.schre s.2017.04.035

Raveendranath V, Nagarajan K, Umamageswari A et al (2019) Threedimensional magnetic resonance-based morphometry of pituitary stalk. Radiol Med 124(3):206-210. https://doi.org/10.1007/s1154 7-018-0956-6

Renz DM, Hahn HK, Schmidt P et al (2011) Accuracy and reproducibility of a novel semi-automatic segmentation technique for MR volumetry of the pituitary gland. Neuroradiology 53(4):233-244. https://doi.org/10.1007/s00234-010-0727-0 
Rhoton AL (2002) The cavernous sinus, the cavernous venous plexus, and the carotid collar. Neurosurgery 51(4):375-410. https://doi. org/10.1227/01.neu.0000028833.01529.e7

Romo-Nava F, Hoogenboom WS, Pelavin PE et al (2013) Pituitary volume in schizophrenia spectrum disorders. Schizophrenia Res 146(1-3):301-307. https://doi.org/10.1016/j.schres.2013.02.024

Ronchetti SA, Miler EA, Duvilanski BH, Cabilla JP (2013) Cadmium mimics estrogen-driven cell proliferation and prolactin secretion from anterior pituitary cells. PLoS ONE 8(11):e81101. https:// doi.org/10.1371/journal.pone.0081101

Roppolo HMN, Latchaw RE, Meyer JD, Curtin HD (1983) Normal pituitary gland: I. Macroscopic anatomy-CT correlation. AJNR 4(4):927-935. Retrieved from http://www.ncbi.nlm.nih.gov/ pubmed/6410877

Sahni D, Jit I, Neelam Harjeet, Bhansali A (2006) Weight and dimensions of the pituitary in northwestern Indians. Pituitary 9(1):1926. https://doi.org/10.1007/s11102-006-7503-5

Sari S, Sari E, Akgun V et al (2014) Measures of pituitary gland and stalk: from neonate to adolescence. J Pediatr Endocrinol Metabol 27(11-12):1071-1076. https://doi.org/10.1515/jpem-2014-0054

Sassi RB, Nicoletti M, Brambilla P et al (2001) Decreased pituitary volume in patients with bipolar disorder. Biol Psychiatry 50(4):271-280. https://doi.org/10.1016/S0006-3223(01)01086-1

Satogami N, Miki Y, Koyama T et al (2010) Normal Pituitary Stalk: high-resolution MRI at 3T. AJNR 31(2):355-359. https://doi. org/10.3174/ajnr.A1836

Scheithauer BW, Horvath E, Kovacs K (1992) Ultrastructure of the neurohypophysis. Microsc Res Tech 20(2):177-186. https://doi. org/10.1002/jemt.1070200206

Schroeder AC, Privalsky ML (2014) Thyroid hormones, T3 and T4, in the brain. Front Endocrinol. https://doi.org/10.3389/fendo .2014 .00040

Schwartz PJ et al (1997) Seasonality and pituitary volume. Psychiatry Res 4;74(3):151-7. Retrieved from https://www.ncbi.nlm.nih. gov/pubmed/9255860

Scott LV, Dinan TG (1998) Vasopressin and the regulation of hypothalamic-pituitary-adrenal axis function: implications for the pathophysiology of depression. Life Sci 62(22):1985-1998. Retrieved from https://doi.org/10.1016/S0024-3205(98)00027-7

Shah S, Waldman AD, Mehta A (2012) Advances in pituitary imaging technology and future prospects. Best Pract Res Clin Endocrinol Metab 26(1):35-46. https://doi.org/10.1016/j.beem.2011.08.003

Shah JL, Tandon N, Howard ER et al (2015) Pituitary volume and clinical trajectory in young relatives at risk for schizophrenia. Psychol Med 45(13):2813-2824. https://doi.org/10.1017/S0033 29171500077X

Smith SM, Vale WW (2006) The role of the hypothalamic-pituitaryadrenal axis in neuroendocrine responses to stress. Dialogues Clin Neurosci 8(4):383-395. Retrieved from http://www.ncbi. nlm.nih.gov/pubmed/17290797

Takahashi T, Malhi GS, Wood SJ et al (2009) Increased pituitary volume in patients with established bipolar affective disorder. Prog Neuropsychopharmacol Biol Psychiatry 33(7):1245-1249. https ://doi.org/10.1016/j.pnpbp.2009.07.012

Takahashi T, Walterfang M, Wood SJ et al (2010) Pituitary volume in patients with bipolar disorder and their first-degree relatives. Journal Affect Disord 124(3):256-261. https://doi.org/10.1016/j. jad.2009.12.002

Takahashi T, Nakamura K, Nishiyama S et al (2013) Increased pituitary volume in subjects at risk for psychosis and patients with firstepisode schizophrenia. Psychiatry Clin Neurosci 67(7):540-548. https://doi.org/10.1111/pen.12093
Takano K, Utsunomiya H, Ono H et al (1999) Normal development of the pituitary gland: assessment with three-dimensional MR volumetry. AJNR 20(2):312-315. Retrieved from http://www. ncbi.nlm.nih.gov/pubmed/10094362

Terano T, Seya A, Tamura Y et al (1996) The relation between the lack of the posterior pituitary bright signal on MRI and posterior pituitary hormone in elderly subjects. Pathophysiology 3(3):163-167. https://doi.org/10.1016/0928-4680(96)00010-7

Theunissen E, Baeten K, Vanormelingen L et al (2010) Detailed visualization of the functional regions of the rat pituitary gland by high-resolution T2-weighted MRI. Anat Histol Embryol 39(3):194-200. https://doi.org/10.1111/j.1439-0264.2010.00995 .x

Thomas L (2004) Pituitary volumes in pediatric maltreatment-related posttraumatic stress disorder. Biol Psychiatry 55(7):752-758. https://doi.org/10.1016/j.biopsych.2003.11.021

Toni R (2000) Ancient views on the hypothalamic-pituitary-thyroid axis: a historical and epistemological perspective. Pituitary 3(2):83-95. https://doi.org/10.1023/A:1009953723963

Tournikioti K, Tansella M, Perlini C et al (2007) Normal pituitary volumes in chronic schizophrenia. Psychiatry Res Neuroimaging 154(1):41-48. https://doi.org/10.1016/j.pscychresns.2006.04.004

Tullo $\mathrm{S}$ et al (2018) Warping an atlas derived from serial histology to 5 high-resolution MRIs. Sci data 5:180107

Upadhyaya AR, El-Sheikh R, MacMaster FP et al (2007) Pituitary volume in neuroleptic-naïve schizophrenia: a structural MRI study. Schizophrenia Res 90(1-3):266-273. https://doi.org/10.1016/j. schres.2006.09.033

Vale W, Spiess J, Rivier C, Rivier J (1981) Characterization of a 41-residue ovine hypothalamic peptide that stimulates secretion of corticotropin and beta-endorphin. Science 18;213(4514): 1394-7. https://doi.org/10.1126/science.6267699

Walter A, Studerus E, Smieskova R et al (2015) Pituitary gland volume in at-risk mental state for psychosis: a longitudinal MRI analysis. CNS Spectr 20(2):122-129. https://doi.org/10.1017/S109285291 $400011 X$

Whittle S, Yücel M, Lorenzetti V et al (2012) Pituitary volume mediates the relationship between pubertal timing and depressive symptoms during adolescence. Psychoneuroendocrinology 37(7):881-891. https://doi.org/10.1016/j.psyneuen.2011.10.004

Wong APY, Pipitone J, Park MTM et al (2014) Estimating volumes of the pituitary gland from T1-weighted MRI: effects of age, puberty, testosterone, and estradiol. NeuroImage 94:216-221. https://doi.org/10.1016/j.neuroimage.2014.02.030

Yamamoto A, Oba H, Furui S (2013) Influence of age and sex on signal intensities of the posterior lobe of the pituitary gland on T1-weighted images from 3 T MRI. Jpn J Radiol 31(3):186-191. https://doi.org/10.1007/s11604-012-0168-2

Yeung CM, Chan CB, Leung PS, Cheng CHK (2006) Cells of the anterior pituitary. Int J Biochem Cell Biol 38(9):1441-1449. https:// doi.org/10.1016/j.biocel.2006.02.012

Zimmerman EA, Robinson AG (1976) Hypothalamic neurons secreting vasopressin and neurophysin. Kidney Int 10(1):12-24. https:// doi.org/10.1038/ki.1976.75

Zipursky AR, Whittle S, Yücel M et al (2011) Pituitary volume prospectively predicts internalizing symptoms in adolescence. $\mathrm{J}$ Child Psychol Psychiatry 52(3):315-323. https://doi.org/10.11 $11 /$ j.1469-7610.2010.02337 